\title{
Remarkable sequence similarity between the dinoflagellate-infecting marine girus and the terrestrial pathogen African swine fever virus
}

\author{
Hiroyuki Ogata ${ }^{1}$, Kensuke Toyoda ${ }^{2}$, Yuji Tomaru², Natsuko Nakayama², \\ Yoko Shirai ${ }^{2}$, Jean-Michel Claverie ${ }^{1}$ and Keizo Nagasaki*2
}

Address: ${ }^{1}$ Information Génomique et Structurale, CNRS-UPR2589, Institut de Microbiologie de la Méditerranée, Parc Scientifique de Luminy, AixMarseille Université, 163 Avenue de Luminy, Case 934, 13288 Marseille Cedex 9, France and ${ }^{2}$ Harmful Algal Bloom Division, National Research Institute of Inland Sea, Fisheries Research Agency, 2-17-5 Maruishi, Hatsukaichi, Hiroshima 739-0452, Japan

Email: Hiroyuki Ogata - Hiroyuki.Ogata@igs.cnrs-mrs.fr; Kensuke Toyoda - kntoyoda@affrc.go.jp; Yuji Tomaru - tomaruy@affrc.go.jp; Natsuko Nakayama - nnakayama@affrc.go.jp; Yoko Shirai - anomalocaris10piki@hotmail.com; Jean-Michel Claverie - jean-

michel.claverie@univmed.fr; Keizo Nagasaki* -nagasaki@affrc.go.jp

* Corresponding author

Published: 27 October 2009

Virology Journal 2009, 6:178 doi:10.1186/1743-422X-6-178

This article is available from: http://www.virologyj.com/content/6/1/178

(c) 2009 Ogata et al; licensee BioMed Central Ltd.

This is an Open Access article distributed under the terms of the Creative Commons Attribution License (http://creativecommons.org/licenses/by/2.0), which permits unrestricted use, distribution, and reproduction in any medium, provided the original work is properly cited.
Received: 24 September 2009

Accepted: 27 October 2009

\begin{abstract}
Heterocapsa circularisquama DNA virus ( $\mathrm{HcDNAV}$; previously designated as $\mathrm{HcV}$ ) is a giant virus (girus) with a $\sim 356-k b p$ double-stranded DNA (dsDNA) genome. HcDNAV lytically infects the bivalve-killing marine dinoflagellate $H$. circularisquama, and currently represents the sole DNA virus isolated from dinoflagellates, one of the most abundant protists in marine ecosystems. Its morphological features, genome type, and host range previously suggested that HcDNAV might be a member of the family Phycodnaviridae of Nucleo-Cytoplasmic Large DNA Viruses (NCLDVs), though no supporting sequence data was available. NCLDVs currently include two families found in aquatic environments (Phycodnaviridae, Mimiviridae), one mostly infecting terrestrial animals (Poxviridae), another isolated from fish, amphibians and insects (Iridoviridae), and the last one (Asfarviridae) exclusively represented by the animal pathogen African swine fever virus (ASFV), the agent of a fatal hemorrhagic disease in domestic swine. In this study, we determined the complete sequence of the type B DNA polymerase (PolB) gene of HcDNAV. The viral PolB was transcribed at least from $6 \mathrm{~h}$ post inoculation (hpi), suggesting its crucial function for viral replication. Most unexpectedly, the HcDNAV PolB sequence was found to be closely related to the PolB sequence of ASFV. In addition, the amino acid sequence of HcDNAV PolB showed a rare amino acid substitution within a motif containing highly conserved motif: YSDTDS was found in HcDNAV PolB instead of YGDTDS in most dsDNA viruses. Together with the previous observation of ASFV-like sequences in the Sorcerer II Global Ocean Sampling metagenomic datasets, our results further reinforce the ideas that the terrestrial ASFV has its evolutionary origin in marine environments.
\end{abstract}

\section{Findings}

Dinoflagellates (Dinophyceae) are one of the highly abundant and ubiquitous unicellular eukaryotic ("protistan") components in marine environments [1]. They constitute a major class of eukaryotes within the Alveolata, a firmly established deep phylogenetic lineage that includes other diverse classes of protists, such as apicomplexans and ciliates [2]. Some dinoflagellates are autotrophic using photo- 
synthesis, some are heterotrophic using endocytotic feeding, and many dinoflagellates are mixotrophic having both modes of nutrition. Blooms of certain photosynthetic dinoflagellates kill fish and bivalves, or pollute shellfishes for food with particular toxins, and can lead to serious economic damages in aquaculture $[3,4]$. Heterocapsa circularisquama forms blooms causing massive death of shellfish such as pearl oysters and mussels, and is one of the most intensively studied dinoflagellate species [5].

HcDNAV is a marine giant virus (or "girus" $[6,7]$ ) containing dsDNA genome, and lytically infects $H$. circularisquama $[8,9]$. HcDNAV is considered to play a significant role in the demise of $H$. circularisquama blooms $[9,10]$. HcDNAV has a large icosahedral capsid (180-210 nm in diameter), which packs a 356-kbp genome $[8,11]$. During its multiplication, virions emerge from a specific cytoplasm compartment, called "viroplasm", which is created by the virus [9]. HcDNAV is the sole DNA virus currently isolated from dinoflagellates, and to our knowledge, is the only DNA virus isolated from the superphylum Alveolata [12]. Based on its host range, genome type/size and microscopic features, HcDNAV was previously suggested to be a member of Phycodnaviridae [13]. However, there has been no molecular data supporting this tentative classification.

Phycodnaviridae includes intensively-studied algal virus members such as chlorella viruses and Emiliania huxleyi viruses [1417], and belongs to a larger group of eukaryotic DNA viruses called NCLDVs [18]. NCLDVs complete their replication cycle within the host cytoplasm, and share an array of conserved core genes for transcription, RNA processing, replication, DNA packaging, and structural components. Other viral families of NCLDVs are Mimiviridae, Poxviridae, Iridoviridae, and Asfarviridae. Mimiviridae is represented by the freshwater amoebainfecting mimivirus [19] and its close relative mamavirus [20]. Based on the sequences of PolB, the most conserved NCLDV core genes, three algal viruses have been suggested to belong to Mimiviridae [21]. Poxviridae include a number of successful pathogens known to infect a tremendous variety of terrestrial animals, such as insects, reptiles, birds, and mammals [22]. Iridoviruses infect invertebrate and cold-blooded vertebrate hosts, and includes numerous emerging pathogens of fishes and amphibians [23]. The last family Asfarviridae [24,25] is currently represented by a sole species, African swine fever virus (ASFV) with a $170 \mathrm{kbp}$ dsDNA genome [26]. ASFV is a large ( $200 \mathrm{~nm}$ in diameter), intracytoplasmically-replicating arbovirus, naturally maintained in a sylvatic cycle between wild swine (warthogs and bushpigs) and argasid ticks (Ornithodoros). In these hosts, ASFV infection is usually asymptomatic [27]. However, ASFV causes an acute hemorrhagic infection in domestic swine with mortality rates up to $100 \%$ for some viral isolates.

In an attempt to further characterize HcDNAV, we performed a low coverage shotgun sequencing of its genome. Specifically, from 4 liters of HcDNAV suspension (lysate of HcDNAVinfected $H$. circularisquama on $6 \mathrm{dpi}$ ), virus particles were collected as described in [11]. The viral genomic DNA was purified in a PFGE-gel and was subjected to shotgun sequencing (coverage $=0.11 \mathrm{X}$ ). Resulting sequence reads covered part of the region containing a PolB-like sequence. With the use of tail-PCR method [28], we successfully determined a 5,800 bp sequence (DDBJ accession number AB522601) containing an open reading frame (ORF) for the complete HcDNAV PolB gene. By means of a reverse transcription-PCR (RT-PCR) experiment, the PolB gene was shown to be transcribed to mRNA (additional file 1); thus, it is most likely crucial for the replication of HcDNAV.

HcDNAV PolB gene was found to be 3,675 bp long (forward strand, position $=$ nt 1,913-5,590 in AB522601), punctuated by normal start and stop codons, and no intron or intein-like sequence was observed. The predicted protein product is 1,225 amino acids (aa) long. Unexpectedly, the translated amino acid sequence showed the closest BLASTP hits against PolB sequences from different ASFV isolates, with the best homolog being DPOL_ASFL6 (identity $=27 \%$, bit score $=311$, E-value = 4.10E-82) in the NCBI non-redundant sequence database. The best non-ASFV hit corresponded to the PolB sequence of Pyramimonas orientalis virus (DPOL_POV01, identity = $23 \%$, bit score $=131$, E-value $=4.10 \mathrm{E}-28)$. A multiple sequence alignment of the HcDNAV PolB and its close homologs confirmed the presence of conserved residues for exonuclease and polymerase activities [29] (additional file 2). Curiously, the HcDNAV PolB sequence exhibited a rarely observed amino acid substitution within the motif containing two highly conserved metal binding aspartic acid residues; HcDNAV exhibits the motif YSDTDSinstead of the YGDTDS- sequence usually found in dsDNA viruses. In addition, we identified two ORFs in the upstream region of the PolB ORF in a divergent orientation. Their products were respectively predicted to be 245 and 194 aa in length (positions = nt 463-1,200 and 1,2551,839 ). The former showed a significant similarity to HNH endonucleases with its BLASTP best hit to mimivirus L245 (YP_142599, E-value = 4E-11); the latter showed a significant similarity to hypothetical proteins from NCLDVs with its best hit to mimivirus R325 (annotated as a metal-dependent hydrolase, YP_142679.1, E-value = 1E12). Incidentally, R325 is located near the PolB gene (R322) in the mimivirus genome [30].

To examine the unexpected sequence similarity between the HcDNAV and ASFV PolBs, we conducted a series of maximum likelihood phylogenetic analyses. First, we aligned the HcDNAV PolB sequence with its homologs from NCLDVs. A phylogenetic tree based on the 362 amino acid residue sites from the alignment supported the monophyletic grouping of HcDNAV and ASFV with a $100 \%$ bootstrap value (Fig. 1). The grouping of each of the 


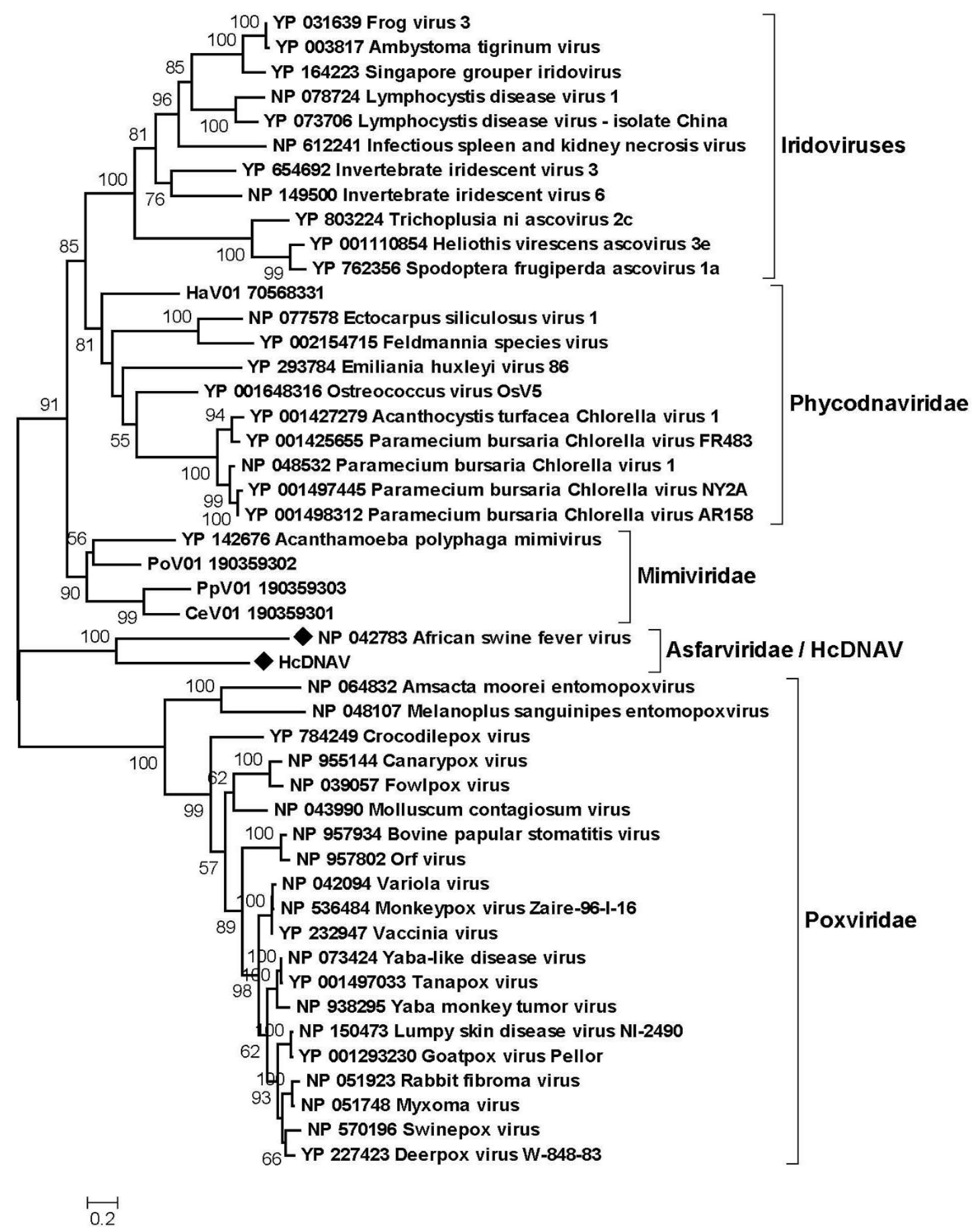

Figure I

Maximum likelihood tree of PolB amino acid sequences from NCLDVs. Alignment was constructed with the use of T-Coffee. All the gap-containing amino acid residue sites were removed before tree construction. The phylogenetic tree was constructed using PhyML [38] available at Phylogeny.fr [39] using WAG matrix and gamma distribution. Branch labels indicate bootstrap percentages $(\geq 50 \%)$ after 100 replicates. The tree is essentially an unrooted tree, albeit mid-point rooted only for presentation purpose. The same method was used for the phylogenetic trees in Fig. 2, Fig. 3 and in the additional file 3. HcDNAV and ASFV sequences are indicated by filled diamond marks. CeV: Chrysochromulina ericina virus; PoV: Pyramimonas orientalis virus; $\mathrm{HaV}$ : Heterosigma akashiwo virus. 


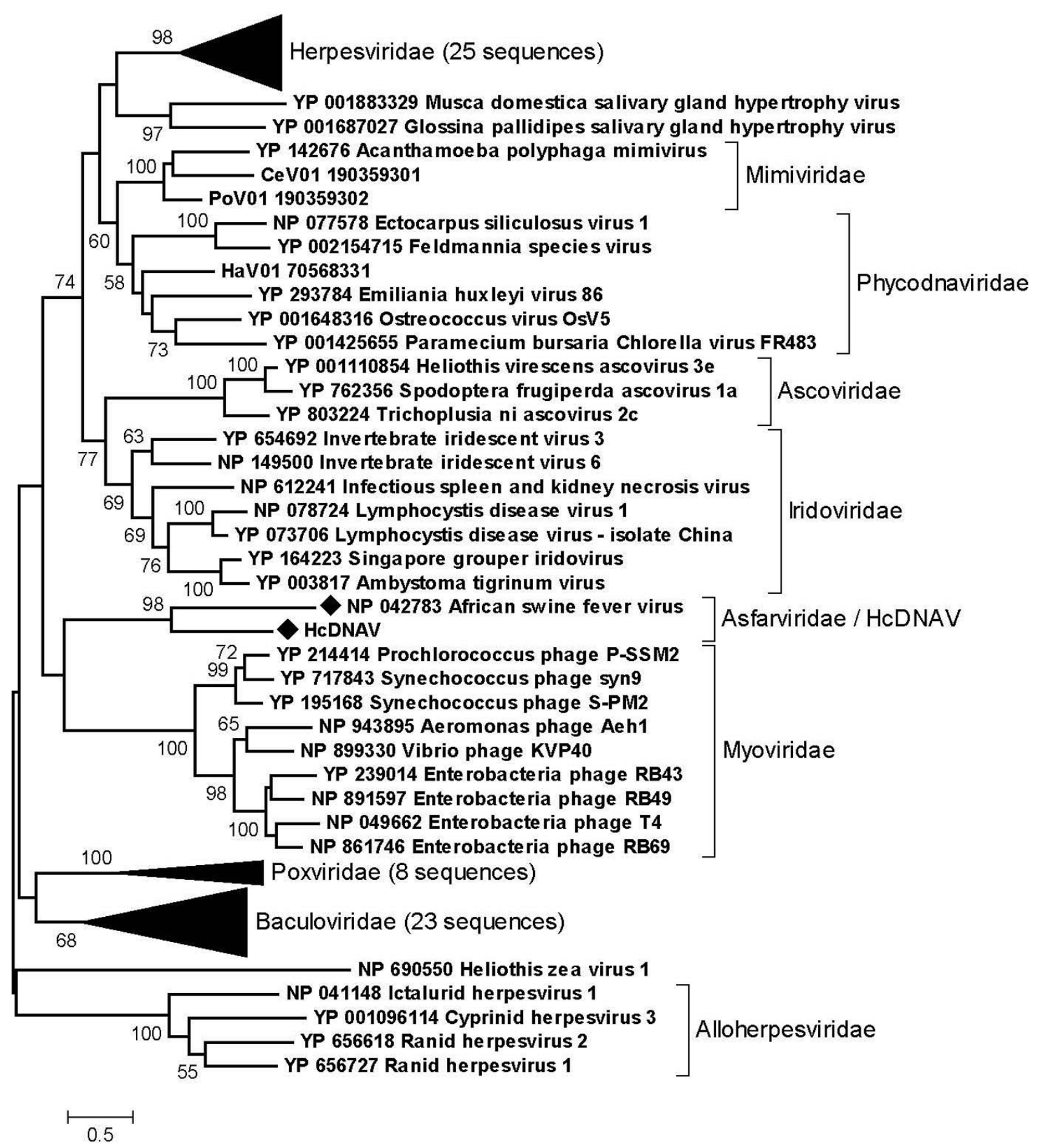

Figure 2

Maximum likelihood tree of PolB amino acid sequences from diverse groups of viruses. HcDNAV and ASFV sequences are indicated by filled diamond marks. 


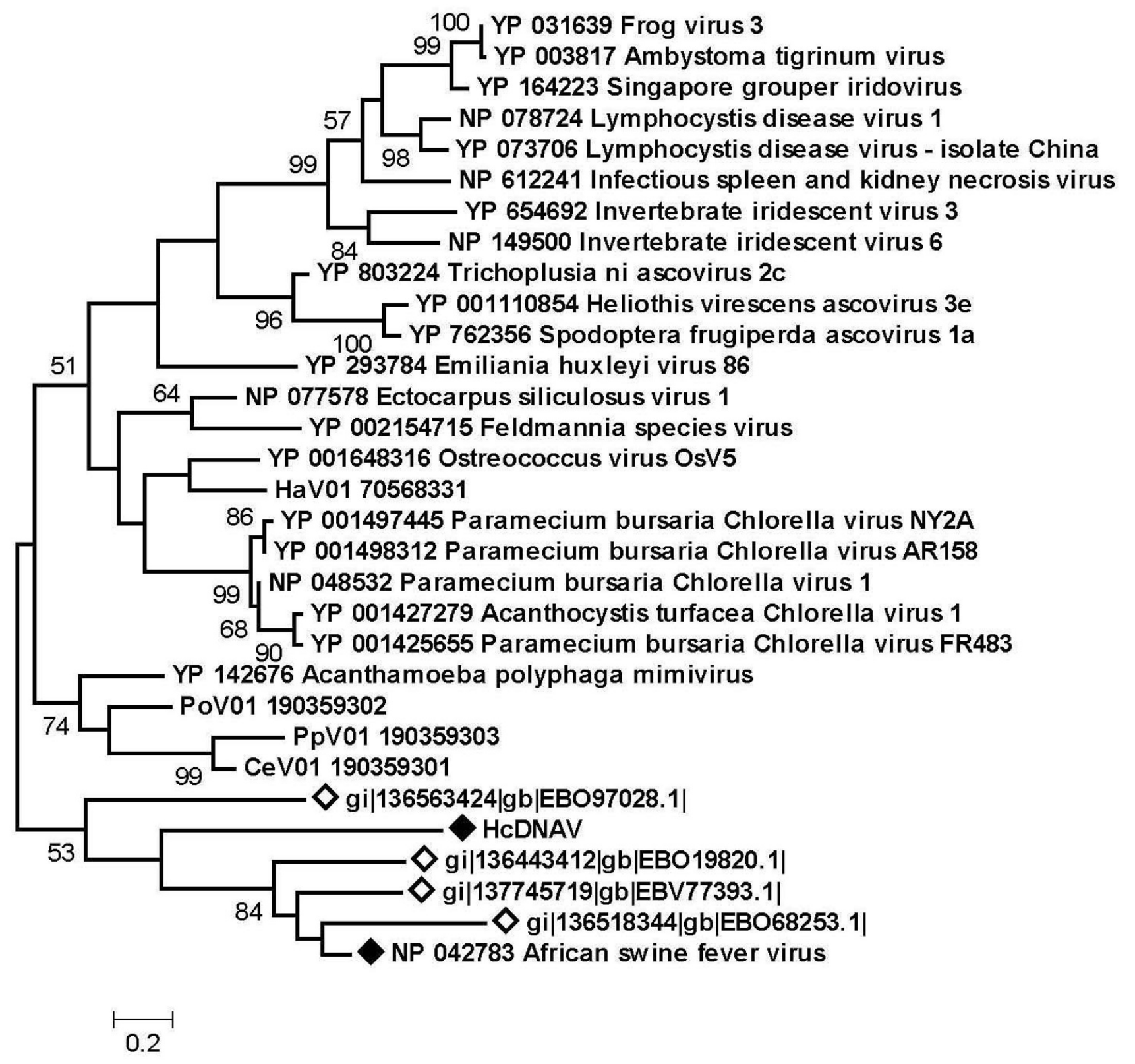

Figure 3

Maximum likelihood tree of PolB amino acid sequences from NCLDVs and several sequences from environmental samples (indicated by open diamond marks). HcDNAV and ASFV sequences are indicated by filled diamond marks.

other four NCLDV families was also supported by a high bootstrap value (100\% for Iridoviridae, 81\% for Phycodnaviridae, $90 \%$ for Mimiviridae and $100 \%$ for Poxviridae). Next, we used a wider range of viral homologs including those of bacteriophages. The resulting tree based on 320 amino acid residues again supported the grouping of HcDNAV/ASFV with a $98 \%$ bootstrap value (Fig. 2).
In addition, we obtained a short sequence partially corresponding to an RNA polymerase II large subunit gene from HcDNAV genomic DNA (AB522602), for which we obtained a similar result. The 892 bp sequence showed BLASTX best hit against ASFV RNA polymerase sequence (RPB1_ASFM2, E-value = 2E-12). A monophyletic grouping between the HcDNAV sequence (97 aa) and the ASFV 
RNA polymerase sequence was again received a high bootstrap value of $87 \%$ (additional file 3 ).

Our homology search and phylogenetic analyses thus confirm that the newly determined HcDNAV sequences are most closely related to their ASFV homologs. This result is in clear contradiction with the previous proposal that HcDNAV may belong to the Phycodnaviridae [13].

A previous "phylogenetic mapping" survey of the metagenomic sequence data sets generated by the Global Ocean Sampling (GOS) expedition [31] revealed several PolBlike sequences most closely related to the PolB sequence of ASFV [32]. This observation suggested the presence of ASFV-related viruses in marine environments. In order to examine whether the "ASFV-like" marine PolB sequences were close to the HcDNAV PolB sequence, we retrieved 267 sequences from the environmental sequence collection of NCBI/GenBank using the PolB sequences of HcD$\mathrm{NAV}$ and ASFV as queries (E-value < 1E-10). These environmental sequences were in turn searched against the NCBI non-redundant sequence database and the HcDNAV PolB sequence. Of the 267 sequences, 15 showed their best hit to the ASFV PolB, one showed its best hit to HcDNAV (gi|136563424), and the remaining sequences had their best hit to other viruses or cellular organisms. Therefore, most of the ASFV/HcDNAV-like PolB sequences in the marine environmental collection are more closely related to the ASFV PolB than to the HcDNAV homolog. A phylogenetic tree using several environmental sequences supported their grouping with the terrestrial ASFV PolB (bootstrap value = 84\%, Fig. 3).

PolB is one of the most reliable phylogenetic markers for large eukaryotic DNA viruses $[32,33]$. The fact that the HcDNAV PolB was not grouped with the PolBs from phycodnaviruses strongly argues against the previous tentative classification of HcDNAV in the Phycodnaviridae family [13]. It is clear that the definitive classification of HcDNAV will require the complete sequencing of its genome. It may also turn out that the HcDNAV genome corresponds to a mosaic of NCLDV genes with different evolutionary histories, precluding a simple classification scheme. Pending its complete genome sequencing, we recently proposed to the ICTV to create a new genus "Dinodnavirus" where to tentatively classify the HcDNAV.

Our finding now establishes an evolutionary link between a terrestrial pathogen and a marine girus. A recent metagenomic analysis of corals provided evidence for the existence of viruses related to herpesviruses [34], which have been mostly isolated as pathogens of terrestrial animals. So far, giruses of 7 algal classes $[12,35]$ have been isolated; still, we know next to nothing about viruses infecting other protists in aquatic environments. Given the huge diversity of protists $[36,37]$, a comparable diversity probably exists for marine viruses living in these environments. Exploring this hidden viral world is necessary to our understanding of the evolutionary relationships between aquatic viruses and their terrestrial relatives.

\section{Competing interests}

The authors declare that they have no competing interests.

\section{Authors' contributions}

NK conceived the study. YS, KT and NN conducted purification and sequencing of HcDNAV and RT-PCR experiment. HO designed and carried out bioinformatics analyses. HO, JMC, YT and NK contributed to the interpretation of data and wrote the manuscript. All authors read and approved the final manuscript.

\section{Additional material}

\section{Additional file 1}

Transcription of the PolB gene of HcDNAV. To verify the transcription of the HcDNAV PolB gene, reverse transcription-PCR (RT-PCR) experiment was conducted. The total RNA samples were isolated from $\mathrm{HcD}$ NAV-inoculated Heterocapsa circularisquama cells collected at $0,1,6$, 12, and $24 \mathrm{hpi}$, then reverse-transcribed according to the method given by Nagasaki et al. [10]. PCR amplification was performed using a DNA polymerase KOD FX (Toyobo, Osaka, Japan) and primers designed for amplification of HcDNAV PolB gene fragment (01F: ACG TTT TAA ATG ATG TTA TTA ATG, 01R: GCC ATT TTA ATA TAT GAA TAA A); the reaction cycling conditions were $94^{\circ} \mathrm{C}$ for 2 min, then 25 cycles of $98^{\circ} \mathrm{C}$ for $10 \mathrm{~s}, 50^{\circ} \mathrm{C}$ for $30 \mathrm{~s}, 68^{\circ} \mathrm{C}$ for $1 \mathrm{~min}$. Lanes 1 to 5 show the RTPCR fragments amplified from cDNAs at 0, 1, 6, 12, and $24 \mathrm{hpi}$, respectively, and lane 6 shows the PCR fragments amplified from HcDNAV DNA (positive control).

Click here for file

[http://www.biomedcentral.com/content/supplementary/1743422X-6-178-S1.JPEG]

\section{Additional file 2}

Conserve blocks from the multiple sequence alignment of PolB sequences from NCLDVs. The data provided shows the presence of conserved residues for exonuclease and polymerase activities in the HcDNAV PolB and its close homologs. Species abbreviation is followed by a database sequence identifier. Intein sequences were removed from the sequences prior to alignment. The alignment was generated by T-Coffee [40] and ClustalX [41]. AmEPV: Amsacta moorei entomopoxvirus ' $L$ '; APMV: Acanthamoeba polyphaga mimivirus; ASFV: African swine fever virus; $\mathrm{CeV}$ : Chrysochromulina ericina virus; EhV: Emiliania huxleyi virus 86; EsV: Ectocarpus siliculosus virus 1; FsV: Feldmannia species virus; $\mathrm{HaV}$ : Heterosigma akashiwo virus 01; HcDNAV: Heterocapsa circularisquama DNA virus; HvAv: Heliothis virescens ascovirus $3 e$; IIV: Invertebrate iridescent virus 6; LCDV: Lymphocystis disease virus 1; OtV: Ostreococcus virus OsV5; PBCV: Paramecium bursaria Chlorella virus 1; PoV: Pyramimonas orientalis virus; VAR: Variola virus. Click here for file

[http://www.biomedcentral.com/content/supplementary/1743422X-6-178-S2.JPEG] 


\section{Additional file 3}

Maximum likelihood tree of RNA polymerase large subunit amino acid sequences. The tree is based on an alignment containing 66 amino acid residues with no gaps. Alignment and tree construction method is the same as those used for the tree in Fig. 1. HcDNAV and ASFV sequences (indicated by filled diamond marks) are grouped and supported by a bootstrap of $87 \%$.

Click here for file

[http://www.biomedcentral.com/content/supplementary/1743422X-6-178-S3.JPEG]

\section{Acknowledgements}

This work was in part supported by the PACA-Biolnfo Platform and Marseille-Nice Genopole.

\section{References}

I. Falkowski PG, Katz ME, Knoll AH, Quigg A, Raven JA, Schofield O, Taylor F): The evolution of modern eukaryotic phytoplankton. Science 2004, 305:354-360.

2. Gray MW, Lang BF, Burger G: Mitochondria of protists. Annu Rev Genet 2004, 38:477-524.

3. Hallegraeff GM: A review of harmful algal blooms and their apparent global increase. Phycologia 1993, 32:79-99.

4. Erdner D, Dyble J, Parsons ML, Stevens RC, Hubbard KA, Wrabel ML, Moore SK, Lefebvre KA, Anderson DM, Bienfang P, et al.: Centers for Oceans and Human Health: a unified approach to the challenge of harmful algal blooms. Environ Health 2008, 7(Suppl 2):S2.

5. Matsuyama Y: Harmful effect of dinoflagellate Heterocapsa circularisquama on shellfish aquaculture in Japan. Jpn Agr Res Quart 1999, 33:283-293.

6. Claverie JM, Ogata H, Audic S, Abergel C, Suhre K, Fournier PE: Mimivirus and the emerging concept of "giant" virus. Virus Res 2006, II7:133-144.

7. Claverie JM, Ogata $\mathrm{H}$ : Ten good reasons not to exclude giruses from the evolutionary picture. Nat Rev Microbiol 2009, 7:615. author reply 615

8. Tarutani K, Nagasaki K, Itakura S, Yamaguchi M: Isolation of a virus infecting the novel shellfish-killing dinoflagellate Heterocapsa circularisquama. Aquat Microb Ecol 2001, 23:103-III.

9. Nagasaki K, Tomaru Y, Tarutani K, Katanozaka N, Yamanaka S, Tanabe $\mathrm{H}$, Yamaguchi M: Growth characteristics and intraspecies host specificity of a large virus infecting the dinoflagellate Heterocapsa circularisquama. Appl Environ Microbiol 2003 69:2580-2586

10. Tomaru Y, Nagasaki K: Widespread occurrence of viruses lytic to the bivalve-killing dinoflagellate Heterocapsa circularisquama along the western coast of Japan. Plankton Biol Ecol 2004, 5I:I-6.

II. Nagasaki K, Shirai Y, Tomaru Y, Nishida K, Pietrokovski S: Algal viruses with distinct intraspecies host specificities include identical intein elements. Appl Environ Microbiol 2005, 71:3599-3607.

12. Nagasaki K: Dinoflagellates, diatoms, and their viruses. J Microbiol 2008, 46:235-243.

13. Wilson WH, Van Etten JL, Schroeder DS, Nagasaki K, Brussaard C, Delaroque N, Bratbak G, Suttle CA: Phycodnaviridae. In Virus Taxonomy, Eighth Report of the ICTV Edited by: Fauquet CM, Mayo MA, Maniloff J, Desselberger U, Ball LA. London: Elsevier Academic Press; 2005:163-175.

14. Yamada T, Onimatsu H, Van Etten JL: Chlorella viruses. Adv Virus Res 2006, 66:293-336.

15. Van Etten JL: Unusual life style of giant chlorella viruses. Annu Rev Genet 2003, 37: 153-195.

16. Wilson WH, Van Etten JL, Allen MJ: The Phycodnaviridae: the story of how tiny giants rule the world. Curr Top Microbiol Immunol 2009, 328: I-42.
17. Monier A, Pagarete A, de Vargas C, Allen MJ, Read B, Claverie JM, Ogata $\mathrm{H}$ : Horizontal gene transfer of an entire metabolic pathway between a eukaryotic alga and its DNA virus. Genome Res 2009, 19:1441-1449.

18. lyer LM, Balaji S, Koonin EV, Aravind L: Evolutionary genomics of nucleo-cytoplasmic large DNA viruses. Virus Res 2006, II 7:156-184.

19. Claverie JM, Abergel C, Ogata H: Mimivirus. Curr Top Microbiol Immunol 2009, 328:89-121.

20. La Scola B, Desnues C, Pagnier I, Robert C, Barrassi L, Fournous G, Merchat M, Suzan-Monti M, Forterre P, Koonin E, Raoult D: The virophage as a unique parasite of the giant mimivirus. Nature 2008, 455: $100-104$

21. Monier A, Larsen JB, Sandaa RA, Bratbak G, Claverie JM, Ogata H: Marine mimivirus relatives are probably large algal viruses. Virol J 2008, 5:12

22. Upton C, Slack S, Hunter AL, Ehlers A, Roper RL: Poxvirus orthologous clusters: toward defining the minimum essential poxvirus genome. J Virol 2003, 77:7590-7600.

23. Chinchar VG, Hyatt A, Miyazaki T, Williams T: Family Iridoviridae: poor viral relations no longer. Curr Top Microbiol Immunol 2009, 328: $123-170$.

24. Dixon LK, Escribano JM, Martins C, Rock DL, Salas ML, Wilkinson PJ: Asfarviridae. In Virus Taxonomy, Eighth Report of the ICTV Edited by: Fauquet CM, Mayo MA, Maniloff J, Desselberger U, Ball LA. London: Elsevier Academic Press; 2005: I35-I 43.

25. Salas M: African swine fever virus (Asfarviridae). In Encyclopedia of Virology 2nd edition. Edited by: Granoff A, Webster RG. London: Elsevier Academic Press; 1999:30-38.

26. Yáñez RJ, Rodriguez JM, Nogal ML, Yuste L, Enriquez C, Rodriguez JF, Vinuela $E$ : Analysis of the complete nucleotide sequence of African swine fever virus. Virology 1995, 208:249-278.

27. Chapman DAG, Tcherepanov V, Upton C, Dixon LK: Comparison of the genome sequences of non-pathogenic and pathogenic African swine fever virus isolates. J Gen Virol 2008, 89:397-408.

28. Liu YG, Whittier RF: Thermal asymmetric interlaced PCR: automatable amplification and sequencing of insert end fragments from PI and YAC clones for chromosome walking. Genomics 1995, 25:674-681.

29. Ogata $\mathrm{H}$, Raoult $\mathrm{D}$, Claverie JM: A new example of viral intein in Mimivirus. Virol J 2005, 2:.

30. Raoult D, Audic S, Robert C, Abergel C, Renesto P, Ogata H, La Scola $B$, Suzan M, Claverie JM: The I.2-megabase genome sequence of Mimivirus. Science 2004, 306: $1344-1350$

31. Rusch DB, Halpern AL, Sutton G, Heidelberg KB, Williamson S, Yooseph S, Wu D, Eisen JA, Hoffman JM, Remington K, et al.: The Sorcerer II Global Ocean Sampling expedition: northwest Atlantic through eastern tropical Pacific. PLoS Biol 2007, 5:e77.

32. Monier A, Claverie JM, Ogata H: Taxonomic distribution of large DNA viruses in the sea. Genome Biol 2008, 9:RI06.

33. Chen F, Suttle CA: Evolutionary relationships among large double-stranded DNA viruses that infect microalgae and other organisms as inferred from DNA polymerase genes. Virology 1996, 219:170-178.

34. Vega Thurber RL, Barott KL, Hall D, Liu H, Rodriguez-Mueller $B$ Desnues C, Edwards RA, Haynes M, Angly FE, Wegley L, Rohwer FL: Metagenomic analysis indicates that stressors induce production of herpes-like viruses in the coral Porites compressa. Proc Natl Acad Sci USA 2008, 105: 184| 3- I84 I8.

35. Van Etten JL, Lane LC, Meints RH: Viruses and viruslike particles of eukaryotic algae. Microbiol Rev I99I, 55:586-620.

36. Keeling PJ, Burger G, Durnford DG, Lang BF, Lee RW, Pearlman RE, Roger AJ, Gray MW: The tree of eukaryotes. Trends Ecol Evol 2005, 20:670-676

37. Falkowski PG, de Vargas C: Genomics and evolution. Shotgun sequencing in the sea: a blast from the past? Science 2004 , 304:58-60.

38. Guindon S, Gascuel O: A simple, fast, and accurate algorithm to estimate large phylogenies by maximum likelihood. Syst Biol 2003, 52:696-704.

39. Dereeper A, Guignon V, Blanc G, Audic S, Buffet S, Chevenet F, Dufayard JF, Guindon S, Lefort V, Lescot M, et al:: Phylogeny.fr: robust phylogenetic analysis for the non-specialist. Nucleic Acids Res 2008, 36:W465-469. 
40. Notredame C, Higgins DG, Heringa J: T-Coffee: A novel method for fast and accurate multiple sequence alignment. J Mol Biol 2000, 302:205-217.

4I. Thompson JD, Gibson TJ, Plewniak F, Jeanmougin F, Higgins DG: The CLUSTAL_X windows interface: flexible strategies for multiple sequence alignment aided by quality analysis tools. Nucleic Acids Res 1997, 25:4876-4882.

Publish with Bio Med Central and every scientist can read your work free of charge

"BioMed Central will be the most significant development for disseminating the results of biomedical research in our lifetime. " Sir Paul Nurse, Cancer Research UK

Your research papers will be:

- available free of charge to the entire biomedical community

- peer reviewed and published immediately upon acceptance

- cited in PubMed and archived on PubMed Central

- yours - you keep the copyright

Submit your manuscript here:

http://www.biomedcentral.com/info/publishing_adv.asp 